\title{
Relatos de experiência sobre ensino de filosofia no brasil: revisão de escopo e dimensões novikoff
}

\author{
Experience reports on teaching philosophy in brazil: scope review and novikoff \\ dimensions
}

\author{
SILVA, Augusto Santana Palma. Bacharel em Farmácia. Pós-Graduando em Dinâmicas de \\ Desenvolvimento do Semiárido \\ Universidade Federal do Vale do São Francisco (UNIVASF) - campus Petrolina. Av. Jose de Sá \\ Maniçoba, s/n, Centro - Petrolina-PE-Brasil. CEP: 56304917 / Telefone: (87) 2101-6757 / E-mail: a \\ ugustolestat@gmail.com
} SILVA, Sheila Torres Feitosa. Bacharela em Administração. Pós-Graduanda em MBA em Gestão de
Negócios com ênfase em RH

Faculade de Educação Superior de Pernambuco (FACESP) - unidade Petrolina. R. Matias de Albuquerque, $n^{\circ}$ 123. Gercino Coelho - Petrolina-PE-Brasil. CEP: 56306-220 / Telefone: (87) 38662246 / E-mail: sheilinhatdb.feitosa@hotmail.com.br

\section{RESUMO}

A educação deve assegurar o livre exercício da razão enquanto busca formar seres críticos capazes de atuar ativamente na sociedade, perspectiva que torna estratégica o ensino de Filosofia. Atenção especial deve ser dada à cosmovisão e pressupostos acadêmicos adotados pelo educador, variáveis passíveis de identificação pelas Dimensões Novikoff que, conjuntamente ao ensino de Filosofia, assegura identificar fraquezas e fortalezas relacionadas ao processo, que poderão: (1) ser apresentados na forma de Relatos de Experiência e; (2) posteriormente sumarizados. A literatura científica não apresenta estudos de revisão envolvendo o ensino de Filosofia em instituições brasileiras sob a forma de Relatos de Experiência, objetivo do presente estudo. Conduziu-se uma Revisão de Escopo com busca em seis bancos de dados utilizando descritores que deveriam compor a seção Título de manuscritos disponíveis integralmente. Foram recuperadas três citações, que abordaram as dificuldades percebidas e ações desenvolvidas envolvendo professores e estudantes. Envolveram estudantes dos Níveis Fundamental, Médio e Educação de Jovens e Adultos e apontaram para importância da didática, variável que deve ser considerada em futuras pesquisas.

Palavras-chave: educação, ensino, aprendizagem, pesquisa

\begin{abstract}
Education must ensure the free exercise of reason while seeking to form critical beings capable of acting actively in society, a perspective that makes teaching Philosophy a strategy. Special attention should be given to the worldview and academic assumptions adopted by the educator, variables that can be identified by the Novikoff Dimensions which, together with the teaching of Philosophy, ensures the identification of weaknesses and strengths related to the process, which may: (1) be reported in the form of Reports Experience and; (2) later summarized. The scientific literature does not present review studies involving the teaching of Philosophy in Brazilian institutions in the form of Experience Reports, the objective of the present study. A Scope Review was conducted with a search in six databases using descriptors that should be included in the Title section of manuscripts available in full. Three citations were retrieved, which addressed the perceived difficulties and actions developed involving teachers and students. They involved students from Elementary, High School and Youth and Adult Education and pointed out the importance of didactics, a variable that should be considered in future research.
\end{abstract}

Keywords: education, teaching, learning, research 
SILVA, ASP; SILVA, STF (2020)

Relatos de experiência sobre o ensino de filosofia no brasil: revisão de escopo e dimensões novikoff

\section{INTRODUÇÃO}

A educação possui uma qualidade transformadora intrínseca: ela permite que o olhar direcionado a determinado aspecto da realidade sofra alterações na medida em que o processo se desenrola. É o equivalente a ver as coisas "com outros olhos", sugerindo a existência de um jogo de impressões envolvendo a realidade: o que se vê, relata e apreende diz mais acerca da relação entre o sujeito e o objeto observado do que da essência do objeto em si. Como o processo pedagógico envolve a aquisição de novos saberes, resultando na alteração do estado interno daquele que observa, sua relação - consequentemente - para com o objeto observado muda, sem que mudem os objetos (HINCHLIFFE, 2011). Portanto, a verdadeira educação deve ser (simultaneamente) emancipada e emancipatória: ao passo que surge em contextos públicos de exercício da própria razão (MUNIZ, 2019), assegura a aquisição de saberes na forma de experiências pedagógicas significativas (HINCHLIFFE, 2011). Neste sentido - e para além do cumprimento das diretrizes estipuladas pela Lei de Diretrizes e Bases da Educação Nacional (BRASIL, 2005) - a Filosofia e sua práxis em sala de aula surgem como estratégias pedagógicas de interesse, uma vez que: (1) configura-se enquanto exercício conceitual; (2) é um processo dialógico e; (3) possui natureza crítica (MUNIZ, 2019).

Ainda, a importância do ensino de Filosofia encontra-se para além de meros contributos educativos, visto que atua no sentido a contribuir no desenvolvimento de competências que permitam ao educando uma postura crítico-reflexiva acerca não apenas do mundo em que se encontra inserido, mas também nas relações que adota para com os outros e consigo mesmo. Em outras palavras, o ensino e práxis filosóficos atuam no sentido do empoderamento dos indivíduos enquanto membros pertencentes, ativos e transformadores sociais (MUNIZ, 2019). Cabe destacar, contudo, que aquele que aprende é um sujeito (entidade biopsicossocial) imerso em uma determinada realidade histórico-cultural, de tal maneira que o aprendizado configura-se como dimensão contexto- dependente, sendo seus limites e potencialidades determinados em função não apenas de quem ensina e do que é ensinado, mas também de quem aprende (HINCHLIFFE, 2011). Demanda, portanto, processos contextualizados de ensino-aprendizagem.

$O$ processo de ensino-aprendizagem se encontra estruturado na forma de um sistema composto por variáveis de natureza pedagógica (quem ensina, para quem, de que forma e com quais objetivos educacionais) e social (os impactos do processo em termos de permitir o desenvolvimento de uma consciência cidadã). Ou seja, a maneira como os processos ocorrem (bem como o rigor adotado) evidenciam pistas acerca da cosmovisão daquele que ensina, bem como de como o processo é percebido por essa mesma pessoa. Tal lógica, no contexto educativo, fornece pistas: (1) de natureza conceitual e; (2) teórico-práticas acerca do pensar e fazer pesquisa em educação (NOVIKOFF, 2010).

Relatos de Experiência correspondem a um manuscrito síntese das percepções de um pesquisador acerca de determinado processo desenvolvido, sob a perspectiva técnica-científica, em um contexto de observação participante (GIL, 2002). Ou seja, configuram-se simultaneamente enquanto processo e produto de uma pesquisa científica, transcrita sob a forma de um documento 
SILVA, ASP; SILVA, STF (2020)

Relatos de experiência sobre o ensino de filosofia no brasil: revisão de escopo e dimensões novikoff

que evidencia vivências, apreensões e interpretações envolvendo determinado fenômeno (e aqueles que nele participam). Este contexto permite elucidar, neste tipo de documento, aspectos relacionados:

(1)à cosmovisão (pressupostos epistemológicos e teóricos) e; (2) à visão técnico-científica (pressupostos relacionados à sistematização do processo) do autor (COSTA; NOVIKOFF, 2017). Ambos, cosmovisão e visão técnico-científica, compreendem as Dimensões Novikoff, variáveis- síntese do processo do planejamento, condução e elaboração de pesquisas (NOVIKOFF, 2010). Nesta perspectiva, Relatos de Experiência compreendem uma das possíveis estratégias de identificação das fraquezas e fortalezas que norteiam o ensino de Filosofia em instituições de ensino brasileiras, uma vez que informações relevantes acerca: (1) da população envolvida (professores e alunos); (2) do conceito (ensino de Filosofia em seus diversos segmentos educativos) e; (3) do contexto (os próprios relatos) podem ser obtidas, lógica que norteia os estudos de sumarização de evidência na forma de Revisões de Escopo (AROMATARIS et al., 2020).

Contudo, e ainda que esta lógica esteja em sintonia à perspectiva da avaliação da qualidade do ensino (BRASIL, 2005), uma busca na literatura utilizando os termos (1) "relato de experiência" e;

(2) revisão, na plataforma Google Acadêmico (início de junho de 2020) não localiza manuscritos voltados para a sumarização de estudos, na forma de Relatos de Experiência, relacionados ao ensino de Filosofia em instituições de ensino brasileira.

O presente manuscrito, portanto, busca sumarizar Relatos de Experiência associados à práxis do ensino de Filosofia em instituições de ensino brasileiras, sob o formato de uma Revisão de Escopo.

\section{MÉTODOS}

Trata-se de uma Revisão de Escopo sem protocolo de registro (por não envolver temas da Área das Ciências da Saúde) que buscou responder à pergunta "qual a produção científica acerca do ensino de filosofia, na forma de relatos de experiência, em instituições de ensino brasileiras?". A pergunta foi estruturada utilizando-se estratégia SPIDER (COOKE; SMITH; BOOTH, 2012) de formulação, sendo composta pelos elementos a) amostra (Sample); b) fenômeno de interesse (Phenomenon of Interest); c) desenho do estudo (Design); d) avaliação (Evaluation) e; e) tipo de estudo (Research type). Deveriam compor a amostra, (1) relatos de experiência (DER) publicados a qualquer momento e formato (resumo, artigo, trabalho de conclusão de curso etc.); (2) disponíveis integralmente e; (3) abordando, sob quaisquer perspectivas, o ensino de filosofia (PI) em ambientes escolares brasileiros (S). A etapa de busca e seleção foi realizada por ambos os autores, de maneira independente e em seis bancos de dados distintos (Biblioteca Virtual Brasileira de Teses e Dissertações, Biblioteca Virtual em Saúde, Google Acadêmico, Portal de Periódicos da CAPES, Scientific Electronic Library OnLine, Scopus). A estratégia de busca envolveu o emprego de três descritores gerais ("relato de experiência", educação e filosofia), combinados utilizando-se o operador booleano AND ("relato de experiência" AND educação AND filosofia). A estratégia deveria compor a seção Título dos manuscritos, sendo também realizada em inglês ("experience report" AND education AND 
SILVA, ASP; SILVA, STF (2020)

Relatos de experiência sobre o ensino de filosofia no brasil: revisão de escopo e dimensões novikoff

philosophy). A busca foi realizada utilizando-se rede de acesso a internet da Universidade Federal do Vale do São Francisco, campus Centro, Petrolina-PE ao dia 12 de junho de 2020. Após identificação das citações potencialmente relevantes, procedeu-se à leitura de títulos e resumos dos manuscritos e aplicação dos critérios para elegibilidade listados acima (etapa realizada por ambos os autores). Citações indisponíveis ou disponíveis parcialmente ou sob a forma de resumos simples foram excluídos. Após determinação da amostra final, os manuscritos foram lidos integralmente por ambos os autores e as variáveis de interesse foram identificadas e transcritas para fichas de análise de elaboração própria. Foram selecionados dados referentes: a) às informações gerais e; b) às Dimensões Novikoff dos manuscritos. As informações gerais compreenderem dados referentes: (1) à população-alvo (quantitativo, faixa etária e sexo); (2) ao contexto de prática (onde ocorreu, quando e qual a forma de registro utilizada) e; (3) aos desfechos relatos e ou percebidos. Informações referentes às Dimensões Novikoff consideraram as definições propostas por Cristina Novikoff (NOVIKOFF, 2010) em relação às dimensões presentes em qualquer relatório técnico-científico: (1) a cosmovisão do autor (suas hipóteses e objetivos) (dimensão epistemológica); (2) seu alicerce teórico que permite a problematização e crítica da realidade (dimensão teórica); (3) quais caminhos são conhecidos e como serão adotados na condução da pesquisa (dimensão teórica); (4) quais os resultados obtidos (dimensão morfológica) e; (5) quais as inferências realizadas e conclusões percebidas pelo autor (dimensão analítico- conclusiva). Divergências entre os autores foram resolvidas através de consenso, sendo os dados sintetizados na forma de Tabelas. Por se tratar de uma Revisão de Escopo, a avaliação crítica da qualidade dos manuscritos que compõem a amostra final não será realizada. Este manuscrito considerou as diretrizes para elaboração de Revisões de Escopo do Instituto Joanna Brigs (AROMATARIS et al., 2020), e a sua redação considera as diretrizes da recomendação PRISMA para relato de Revisões de Escopo (PRISMA-ScR) (TRICCO et al., 2018).

\section{RESULTADOS}

Após aplicação das estratégias e busca, quatro citações potencialmente relevantes foram identificadas (não foram identificadas citações em duplicata). Após leitura de títulos e resumos e aplicação dos critérios para inclusão e não inclusão, uma citação foi excluída por corresponder a um manuscrito publicado sob a forma de resumo simples. A amostra final é composta por três citações (COSTA; NOVIKOFF, 2017; MUNIZ, 2019; SILVA et al., 2019). Dois deles (COSTA; NOVIKOFF, 2017; SILVA et al., 2019) foram publicados sob a forma de artigos em periódicos e um (MUNIZ, 2019) sob o formato de Trabalho de Conclusão de Curso. Divergências entre os autores ocorreram após a leitura do manuscrito de Muniz (2019), cuja seção específica referente ao Relato de Experiência não trazia elementos que permitissem sua análise sob a perspectiva das Dimensões Novikoff. 0 consenso adotado foi a leitura do manuscrito em sua íntegra por ambos os autores. A Figura 1 a seguir apresenta o diagrama de fluxo adotado pelos pesquisadores na condução desta Revisão de Escopo. 


\section{SILVA, ASP; SILVA, STF (2020)}

Relatos de experiência sobre o ensino de filosofia no brasil: revisão de escopo e dimensões novikoff

Figura 1 - Diagrama de Fluxo da busca sistemática de relatos de experiência envolvendo o ensino de filosofia em instituições de ensino brasileiras.

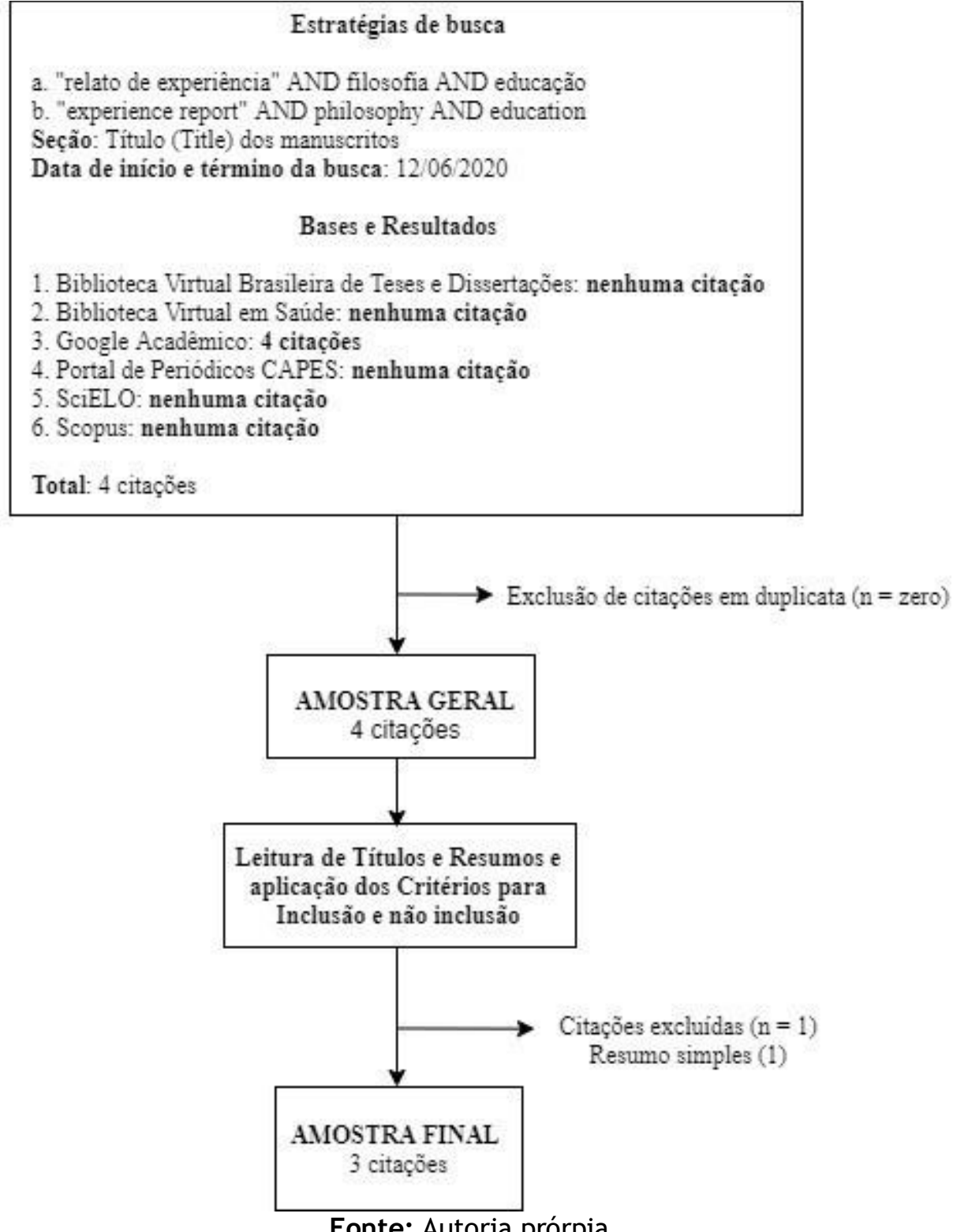

Fonte: Autoria prórpia.

O relato de Costa e Novikoff (2017) surge como consequência das vivências acadêmicas de uma as autoras a partir de aulas ministradas, no período noturno, a jovens e adultos de Filosofia e Sociologia como requisitos parciais relacionados a um Programa de Pós-Graduação em Docência do Ensino Superior e Tecnológico da Faculdade Sul Fluminense. Objetiva, especificamente, descrever os desafios percebidos ao ensino da referida disciplina durante aulas ofertadas no Colégio Evangélico Almeida Barros (Rio de Janeiro), relatados sob a forma de questões relacionadas: (1) à violência e criminalidade locais; (2) à indisponibilidade dos estudantes para participar das aulas, uma vez que era comum que alguns possuíssem emprego e; (3) a indisciplina e ou falta de interesse por parte dos mesmos. 0 público-alvo consistiu de 80 indivíduos de ambos os sexos, com idade entre 15 e 30 anos. Não foram fornecidas informações acerca do período temporal envolvido, nem dos métodos empregados para registro das ações desenvolvidas. 
SILVA, ASP; SILVA, STF (2020)

Relatos de experiência sobre o ensino de filosofia no brasil: revisão de escopo e dimensões novikoff

Muniz (2019) elabora um relato de suas vivências envolvendo o ensino de Filosofia, durante um período de Estágio Supervisionado em uma Escola Estadual de Ensino Médio situada na cidade de Campina Grande, entre setembro e outubro de 2018, para obtenção de título de Licenciatura em Filosofia pela Universidade Estadual da Paraíba. Descreve o contexto educacional relacionado ao ensino de Filosofia na referida instituição e as dificuldades percebidas envolvendo alunos de ambos os sexos do $1^{\circ}, 2^{\circ}$ e $3^{\circ}$ ano do Ensino Médio. A Escola Estadual atua seguindo as diretrizes estipuladas para a Escola Cidadã Integral, com aulas das 07h00min às 17h00min (formação educacional atrelada à formação técnico-profissional). Dificuldades percebidas e relatadas envolveram questões relacionadas: (1) ao fato de, durante o estágio, o país encontrar-se em ano eleitoral para determinação do novo chefe do Executivo brasileiro; (2) questões relacionadas aos movimentos de resistência, por parte de alguns setores educacionais, envolvendo o Projeto Escola sem Partido (relatado pela autora como sendo de cunho negativo em termos de contributo ao processo ensinoaprendizagem em ambientes educacionais); (3) Indisponibilidade de material didático específico; (4) falta de interesse dos alunos pela disciplina, motivada (segundo a autora) pelo fato da instituição encontrar-se em seu ciclo final de preparações para a realização do Exame Nacional do Ensino Médio. Não foram fornecidas informações referentes à faixa etária e quantitativo de alunos, nem em relação à forma de registro sistemático das informações pela autora.

Silva et al. (2019) objetiva o relato descritivo das atividades realizadas e dificuldades percebidas durante a execução do Projeto Filosofia com Crianças, realizado na Escola de Educação Básica Francisco Hoepers (Santa Catarina). Envolveu a participação de professoras e alunos, em dois momentos distintos: No segundo semestre de 2018, ocorreram encontros quinzenais com 25 docentes, voltados (1) ao desenvolvimento de competências voltadas ao ensino, à filosofia e sobre o ato de ensinar filosofia à crianças e; (2) à elaboração de dinâmicas. No primeiro semestre de 2019 (09/06/2019), ocorreram as realizações das dinâmicas, sendo o manuscrito dos autores referentes àquela envolvendo 30 alunos de ambos os sexos do $4^{\circ}$ ano do Ensino Fundamental I. A dinâmica envolveu trabalhar o conceito da palavra "respeito". Os estudantes foram divididos em três grupos, sendo a cada um entregue imagens que deveriam ser acondicionadas em caixas identificadas com os nomes (a) tipo evidente (quando estivesse claro para o grupo que a imagem tinha uma relação evidente com o conceito); (b) tipo oposto (quando a imagem expressasse o contrário ao proposto); (c) tipo próximo (quando não houvesse certeza da proximidade com o conceito) e; (d) tipo absurdo (quando a imagem não correspondesse nem ao evidente nem ao oposto). Os autores relatam boa receptividade por parte das docentes e dos alunos em relação à temática trabalhada. Não foram apresentadas informações acerca da idade dos participantes, nem das estratégias utilizadas para registro das informações. 


\section{SILVA, ASP; SILVA, STF (2020)}

Relatos de experiência sobre o ensino de filosofia no brasil: revisão de escopo e dimensões novikoff

Tabela 1 - Síntese geral de informações referentes à população, ao contexto de prática e aos desfechos relatados e ou percebidos pelos manuscritos selecionados.

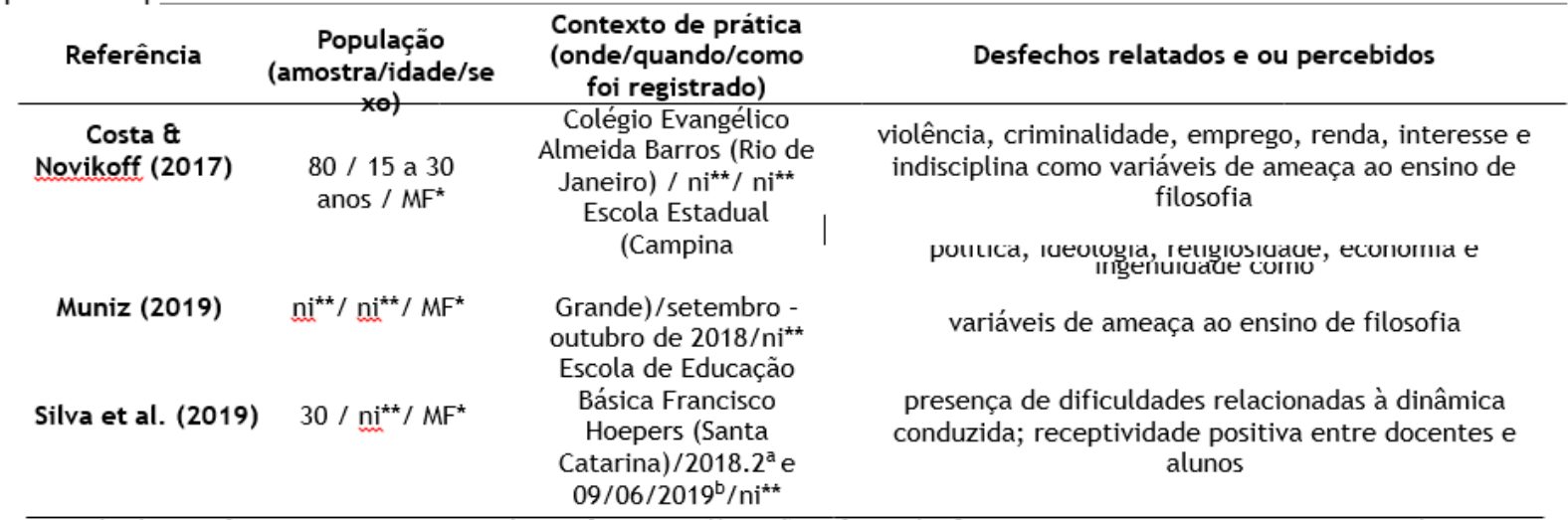

Legenda: ${ }^{*} \mathrm{MF}$ : referente aos sexos masculino e feminino; ${ }^{\star \star}$ ni: não informado; ${ }^{2} 2018.2$ : encontros quinzenais com 25 docentes durante o segundo semestre de 2018; ' $09 / 06 / 2019$ : realização da dinâmica envolvendo 30 alunos do $4^{\circ}$ ano do Ensino

Fundamental I.

Fonte: Autoria própria.

Tabela 2 - Síntese geral de informações referentes às Dimensões Novikoff (NOVIKOFF, 2010) presentes nos manuscritos selecionados.

\begin{tabular}{|c|c|c|c|c|c|}
\hline Referência & Epistemológica & Teórica & Técnica & Morfológica & Analítico-Conclusiva \\
\hline \multirow[t]{3}{*}{ Muniz (2019) } & $\begin{array}{c}\text { Papel emancipador } \\
\text { da Filosofia }\end{array}$ & $\begin{array}{c}\text { LDB }^{*} ; \text { EJA }^{* \star} ; \\
\text { Dimensões } \\
\text { Novikoff Paulo } \\
\text { Freire; Immanuel } \\
\text { Kant; Theodor W. } \\
\text { Adorno; Max } \\
\text { Horkheimer; Sílvio } \\
\text { Gallo }\end{array}$ & $\begin{array}{c}\text { Dimensões } \\
\text { Novikoff } \\
\text { ni }^{* \star \star *}\end{array}$ & $\begin{array}{l}\text { Relato das } \\
\text { dificuldad } \\
\text { es } \\
\text { percebidas }\end{array}$ & $\begin{array}{c}\text { Necessidade de } \\
\text { superação das } \\
\text { dificuldades } \\
\text { percebidas mediante } \\
\text { emprego de } \\
\text { estratégias de } \\
\text { natureza didática }\end{array}$ \\
\hline & rapel ua cr Idrlça nu & & Encontro & & Potencialidades e \\
\hline & \multicolumn{5}{|c|}{ com } \\
\hline $\begin{array}{l}\text { Silva et al. } \\
(2019)\end{array}$ & $\begin{array}{l}\text { processo filosófico } \\
\text { Lipman }\end{array}$ & Matthew & $\begin{array}{l}\text { docentes e } \\
\text { realização de } \\
\text { dinâmica }\end{array}$ & $\begin{array}{l}\text { Relato do } \\
\text { processo }\end{array}$ & $\begin{array}{c}\text { relevância da } \\
\text { criança no } \\
\text { processo }\end{array}$ \\
\hline
\end{tabular}

Legenda: " $L D B:$ Lei de Diretrizes e Bases da Educação Nacional; *^EJA: Educação de Jovens e Adultos; ${ }^{\star \star \star}$ ni: não informado.

Fonte: Autoria própria.

\subsection{Dimensões Novikoff}

Em Costa e Novikoff (2017), a dimensão epistemológica aborda problematização relacionada à importância atribuída à Filosofia (e seu papel emancipador) a partir da perspectiva dos alunos. As motivações das autoras envolveram a contribuição ao processo que permitiria a discussão envolvendo mecanismos de ensino-aprendizagem em termos gerais, englobando desde as estruturas (onde o ensino ocorre), os processos (o ato de ensinar em si) e seus desfechos (os frutos do processo). A dimensão teórica envolveu a Lei de Diretrizes e Bases da Educação Nacional (BRASIL, 2005) no tocante ao ensino de Filosofia e Sociologia. A dimensão técnica complementar considerou a análise da estrutura física do ambiente envolvido, sem disponibilizar informações referentes a dados pessoais dos alunos e processos de registro sistemático das informações. A dimensão morfológica envolveu um relato descritivo do perfil profissional da autora e do contexto educativo (Educação para Jovens e Adultos): indivíduos de ambos os sexos, com idade variando entre 15 e 30 anos (cerca de 80 indivíduos) e frequentando as aulas durante o período noturno. A dimensão analíticoconclusiva envolveu aspectos relacionados (1) aos condicionantes e determinantes sociais, culturais, 
SILVA, ASP; SILVA, STF (2020)

Relatos de experiência sobre o ensino de filosofia no brasil: revisão de escopo e dimensões novikoff

econômicos e políticos que influenciam o aprendizado e; (2) à importância do modelo EJA como estratégia de desenvolvimento de competências inclusivas àqueles que, por motivos diversos, não cumpriram o processo de educação formal nas idades esperadas.

Em Muniz (2019), a dimensão epistemológica envolveu o papel emancipador da Filosofia frente às relações de poder presentes na sociedade. A dimensão teórica envolveu pensadores na forma de Paulo Freire, Immanuel Kant, Theodor W. Adorno, Max Horkheimer e Sílvio Gallo. Não são apresentadas informações referentes à dimensão técnica. A dimensão morfológica compreende o relato das dificuldades percebidas, atribuídas pela autora, na forma da dimensão analíticoconclusiva (a serem superadas) envolvendo variáveis de cunho político, ideológico, religioso, econômico e de ingenuidade.

Silva et al. (2019), em sua dimensão epistemológica aborda a problemática relacionada ao papel estratégico e pouco valorizado da criança no processo filosófico, cuja referência (dimensão teórica) encontra-se na figura de Matthew Lipman. A dimensão técnica compreendeu a descrição dos encontros com os docentes e a realização da dinâmica que abordou o conceito da palavra "respeito". A dimensão morfológica compreendeu o relato global do processo e a dimensão analíticoconclusiva abordou as potencialidades e limitações identificadas, bem como a ratificação da relevância daquele que aprende no processo.

\section{DISCUSSÃO}

Relatos de experiência compreendem pesquisas documentais de cunho qualitativo, representando as vivências, impressões e apreensões dos seus autores quando imersos em determinado fenômeno (o fato relatado). Este contexto torna este tipo de manuscrito, em especial aqueles que não adotam um modelo teórico prévio para análise, mais susceptível a desordens em âmbito lógico, resultando em textos que alternam entre observação, reflexão e interpretação no decorrer do processo de análise (GIL, 2002). As Dimensões Novikoff (NOVIKOFF, 2010), se por um lado não permitem a superação deste fenômeno, por outro asseguram ao seu leitor a capacidade de identificar os aspectos de natureza conceitual e teórico-práticas que norteiam o pensar e o fazer pesquisa por parte do autor. Dito de outra forma, estas dimensões norteiam as crenças, motivações e interesses dos autores quando em relação a determinada temática comum. Para Costa e Novikoff (2017), a Filosofia e seu ensino contextualizado representam uma estratégia norteadora que visa a organização social. Para Muniz (2019), este ensino representaria um meio pelo qual um sujeito poderá emancipar-se, processo no qual tornar-se-ia, verdadeiramente, ser social, político e histórico. Para Silva et al. (2019), este processo deve considerar o aluno em sua tenra idade, fato que demandaria uma eficiente articulação, na forma de planejamento e execução de ações, entre aqueles que ensinam e aqueles destinados a aprender.

Observam-se duas perspectivas nos manuscritos selecionados: (1) interna, voltada para a descrição da impressão dos autores acerca do processo (COSTA; NOVIKOFF, 2017; MUNIZ, 2019) e; (2) externa, voltada para a descrição do processo em si (SILVA et al., 2019). Ambas as perspectivas 
SILVA, ASP; SILVA, STF (2020)

Relatos de experiência sobre o ensino de filosofia no brasil: revisão de escopo e dimensões novikoff

se encontram relacionadas à lógica de discussão educacional, a qual se encontra estruturada sob a perspectiva processos-resultados (ou ensino-aprendizagem) (HINCHLIFFE, 2011). O processo de ensino-aprendizagem se encontra estruturado na forma de um sistema composto por variáveis de natureza pedagógica (quem ensina, para quem, de que forma e com quais objetivos educacionais) e social (os impactos do processo em termos de permitir o desenvolvimento, por parte de quem aprende, de uma consciência cidadã) (NOVIKOFF, 2010), sendo portanto estratégico um olhar direcionado à didática (planejamento, objetivos, mecanismos de avaliação etc.), variável comum aos três manuscritos selecionados, de modo que, por um lado, sejam adotadas estratégias eficientes de ensino-aprendizagem visando a aprendizagem significativa (HINCHLIFFE, 2011) e, por outro, sejam levadas em consideração os diferentes contextos e cenários de práxis educativa, a qual deve ser emancipada e emancipatória (MUNIZ, 2019). Do contrário, tenderá a manter mecanismos que negam as singularidades dos indivíduos, mantendo-os em espirais paradoxais de pseudoindividualidade oriundas de processos sistemáticos e contínuos de manipulação e fragmentação mental, emocional e social (MUNIZ, 2019).

Os estudos selecionados - e respeitadas as suas singularidades - envolveram indivíduos de ambos os sexos, de faixas etárias distintas e contemplando os níveis tradicionais de ensino (Ensino Fundamental e Médio), não envolvendo (1) o cenário do Ensino Superior (Graduação e ou PósGraduação); (2) a população idosa brasileira e; (3) docentes enquanto público-alvo específico (ao invés de intermediário). Ainda, e considerando que o ensino de Filosofia compreende uma das diretrizes da Lei de Diretrizes e Bases da Educação Nacional (BRASIL, 2005), esperar-se-ia maior quantitativo de citações recuperadas, em especial considerando-se: (1) os distintos estratos etários (crianças, jovens e adultos); (2) o universo temporal considerado. Isso pode sugerir uma aparente falta de interesse de publicações envolvendo (1) este formato específico de manuscrito (relato de experiência) e ou (2) temática (ensino de Filosofia) e ou natureza da pesquisa (prática).

Os resultados desta Revisão de Escopo ratificam a importância de atenção especial que deve ser dada ao contexto pedagógico, composto por singulares e heterogêneos, na forma de seus alunos, sistemas de crenças em distintos níveis de cristalização - variável que, em si, exerce influência significativa nas percepções e relação dos indivíduos para com o conhecimento, demandando estratégias específicas de ensino-aprendizagem visando a aprendizagem significativa (COSTA; NOVIKOFF, 2017). No entanto, e ainda que esta lógica se encontre em sintonia à lógica de gestão de ensino enquanto processo corresponsável, pouco (ou muito pouco) se encontra voltado para a perspectiva do objeto-alvo: aquele que aprende (HINCHLIFFE, 2011). Convém destacar, finalmente, que Revisões de Escopo não objetivam a avaliação crítica da qualidade dos manuscritos selecionados (estudos observacionais qualitativos), de modo que a argumentação aqui apresentada evidencia limitações em âmbito geral relacionadas à produção acadêmica envolvendo relatos de experiência acerca do ensino de Filosofia.

As Dimensões Novikoff (NOVIKOFF, 2010), ao considerarem as variáveis epistemológicas, teóricas, técnicas, morfológicas e analítico-conclusivas envolvendo uma pesquisa científica (neste caso relatos de experiência), evidenciam a cosmovisão de um dado sujeito (aquele que escreve) acerca não apenas de um determinado processo (o ato de ensinar Filosofia e quais as problemáticas 
SILVA, ASP; SILVA, STF (2020)

Relatos de experiência sobre o ensino de filosofia no brasil: revisão de escopo e dimensões novikoff

envolvidas), mas de como ele o percebe em âmbito técnico-científico (quais estratégias utilizou) e subjetivo (inquietações relatadas) - e quais seus desfechos (transcritos sob a forma de um relato de experiência cuja ênfase estará voltada ao que foi feito ou a como se sentiu ou ao que se percebeu ao fazê-lo). Assim, Relatos de Experiência, na perspectiva das dimensões propostas por Novikoff, permitem o vislumbre e identificação das fortalezas e fragilidades envolvendo o ensino de Filosofia em instituições de ensino brasileiras, seja relacionado àquilo que vem sendo objeto de estudo, ao que se aborda em sala de aula, ao público-alvo envolvido, à abordagem utilizada e ou as ameaças envolvidas e ou percebidas (TRICCO et al., 2018). Estas variáveis deverão compor estratégias pedagógicas voltadas à práxis pedagógica visando assegurar experiências educacionais significativas, na forma de processos pedagógicos válidos na perspectiva de ambos: aquele que ensina e aquele que aprende (NOVIKOFF, 2010; HINCHLIFFE, 2011).

Ainda que aspectos positivos deste estudo compreendam o universo temporal envolvido, bem como os bancos de dados consultados e a inclusão do idioma inglês, limitações nesta Revisão de Escopo envolveram (1) descritores empregados e estratégias de busca utilizadas; (2) bases consultadas (incluindo literatura cinza e citações indiretas) e; (3) idioma das buscas (por exemplo, espanhol).

\section{CONCLUSÕES}

A literatura científica disponível na forma de Relatos de Experiência envolvendo o ensino de Filosofia em instituições de ensino brasileiras apresenta reduzido número de estudos, contemplando os níveis Fundamental, Médio e Educação de Jovens e Adultos. Os estudos abordam a descrição/percepção das problemáticas envolvidas (relacionadas a aspectos gerais de cunho cultural, econômico e político) ou a descrição das ações realizadas e seus desfechos. Há a percepção da importância da didática no processo ensino-aprendizagem. A Filosofia, e seu ensino, são percebidos como elemento pedagógico estratégico, dada a sua natureza emancipatória social e ou elementar capaz de estimular o desenvolvimento de conhecimentos, habilidades e atitudes de natureza crítico- reflexiva em seus praticantes.

Ao considerar as perspectivas epistemológicas, teóricas, técnicas, morfológicas e analíticoconclusivas, que permitem evidenciar aspectos de natureza técnico-científica atrelados à cosmovisão dos autores, evidenciou-se menor ênfase direcionada às variáveis metodológicas empregadas, figurando variável de interesse relevante a futuras pesquisas. Recomenda-se às futuras publicações que se considerem não apenas os demais estratos de ensino (Ensino Superior), mas também a parcela da população brasileira composta por idosos, enquanto variáveis de natureza didática se façam presentes, envolvendo concepção e execução de uma práxis educadora emancipatória e significativa em termos de experiência. 
SILVA, ASP; SILVA, STF (2020)

Relatos de experiência sobre o ensino de filosofia no brasil: revisão de escopo e dimensões novikoff

\section{REFERÊNCIAS}

AROMATARIS, E.; MUNN, Z. (editores). JBI Reviewer's Manual. JBI, 2020. Disponível em: < h ttps://wiki.joannabriggs.org/display/MANUAL/JBI+Reviewer\%27s+Manual >. Acesso em $21 \mathrm{de}$ junho de 2020.

BRASIL. Lei de Diretrizes e Bases da Educação Nacional. 2005. Disponível em: < https://www2.senado.leg.br/bdsf/bitstream/handle/id/70320/65.pdf >. Acesso em 26 de junho de 2020.

COOKE, Alison; SMITH, Debbie; BOOTH, Andrew. Beyond PICO: the SPIDER tool for qualitative evidence synthesis. Qualitative Health Research, v. 22, n. 10, p. 1435-1443, 2012.

COSTA, Thamiris Gomes da.; NOVIKOFF, Cristina. Desafiando a filosofia na EJA: relato de experiência na educação. Revista de Pesquisa Interdisciplinar, n. 2, p. 745-750, 2017.

GIL, Antônio Carlos. Como elaborar projetos de pesquisa. 4. ed.. São Paulo: Atlas, 2002.

HINCHLIFFE, Geoffrey. What is a significant educational experience? Journal of Philosophy of Education, v. 45, n. 3, p. 417-431, 2011.

MUNIZ, Camila Guedes. Filosofia no ensino médio para a emancipação do pensamento: reflexão das concepções Adornianas sobre educação a partir de um relato de experiência. 2019. 19f. Trabalho de Conclusão de Curso (Graduação em Filosofia) - Universidade Estadual da Paraíba, Campina Grande-PB, 2019.

NOVIKOFF, Cristina. Dimensões Novikoff: um constructo para o ensino-aprendizado da pesquisa. 2010. Disponível em: <

h ttp://www.academia.edu/download/24721969/TEXTO_LIVRO_CN_1_.pdf >. Acesso em 15 de junho de 2020.

SILVA, Alex Sander; FREITAS, Beatris Pizzoni de; AZEREDO, Jeferson Luiz de; CYPRIANO, Vivian Miranda. Filosofia com crianças - a criança na construção de um saber filosófico: um relato de experiência na Escola de Educação Básica Francisco Hoepers. Revista Linguagem, Ensino e Educação, v. 3, n. 1, 2019.

TRICCO, Andrea C. et al.. PRISMA extension for scoping reviews (PRISMA-SCR): checklist and explanation. Annals of Internal Medicine, v. 169, n. 7, p. 467-486, 2018. 